\title{
Geographical distribution and profile of medical doctors in public sector hospitals of the Limpopo Province, South Africa
}

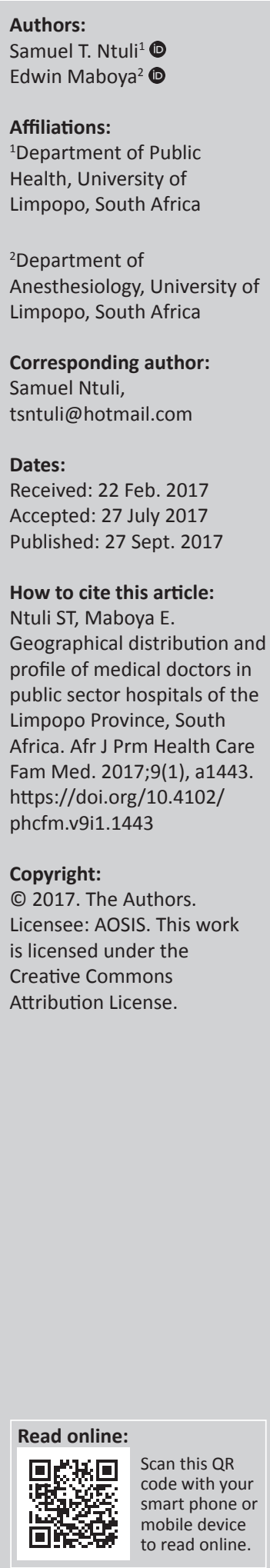

Background: The shortage and unequal distribution of medical doctors in low- and middleincome countries continues to be a public health concern.

Objective: To establish the geographical distribution and demographic profile of medical doctors in public sector hospitals of the Limpopo Province, South Africa.

Method: The PERSAL system was used to obtain information on the number of medical doctors employed in public sector hospitals of the Limpopo Province. Data were exported from PERSAL's database and then analysed using STATA version 9.0.

Result: The mean age of the 887 medical doctors was $40.1 \pm 11.2$ years (range 24-79 years). Sixty per cent of the doctors were male, $66 \%$ were aged $\leq 45$ years and $84 \%$ were African. Most of the doctors (86\%) were medical officers, of which $55 \%$ had $<5$ years working experience. Overall, the doctor-to-population ratio for the five districts in the province was 16.4/100 000, with Capricorn (33.7/100 000) and Waterberg (20.2/100 000) recording the highest ratios. A large proportion $(43 \%)$ of medical officers are employed in the Capricorn District, of which $71 \%$ were practising at the tertiary hospital.

Conclusion: This study demonstrated a shortage and maldistribution of medical doctors in the public sector hospitals of the Limpopo Province. This has a potentially negative effect on the delivery of an appropriate and efficient healthcare service to the population and requires urgent attention.

\section{Introduction}

The proposed National Health Insurance (NHI) by the government of South Africa (SA) is recognised as one of the best and the most responsive ways to improve the life expectancy of a population. ${ }^{1}$ However, this proposed free access and low cost health service in SA is now threatened by lack of infrastructure and shortage of human resources, particularly medical doctors. The shortage and maldistribution of these professionals is a serious problem worldwide, ${ }^{2,3,4,5,6,7}$ whereas the brain drain ${ }^{8}$ and ageing of the workforce are additional problems exacerbating the situation. ${ }^{9,10}$ In SA, the shortage and unequal distribution of medical doctors, with too few doctors servicing rural communities, is not a new phenomenon ${ }^{11,12}$ and has been highlighted in the national media. $13,14,15,16,17$

Several interventions such as training South Africans as doctors in Cuba, compulsory community service for graduate medical doctors, extension of internship to 2 years and the introduction of various financial incentives - such as scarce skills, rural allowances and the recruitment of Cuban doctors - have been tried in order to address shortage of doctors in remote and rural areas. ${ }^{18,19,20,21}$ In 2007 , the SA government introduced the occupation-specific dispensation (OSD) policy, a financial incentive strategy aimed at attracting and retaining health professionals in the public health sector.

To date, it is not known whether the above initiatives are improving or worsening the availability of medical doctors in rural areas of SA, especially in the Limpopo Province. Therefore, the purpose of this study was to establish the geographical distribution and demographic profile of medical doctors in the public sector hospitals of the Limpopo Province, SA.

\section{Methodology}

\section{Study design and population}

The study included all medical officers (MO) (generalists) and specialists working in Limpopo's public sector hospitals. From the PERSAL records as at January 2015, there were 766 MOs and 99 
medical specialists and 22 specialist trainees in Limpopo. Medical specialists and MOs doing their 1-year community service and interns were excluded because they are undertaking training and often placed in public hospitals not of their choice. ${ }^{22,23}$

\section{Study area and setting}

The Limpopo Province is predominantly rural and has an estimated population of 5.5 million people. ${ }^{24}$ The province is strategically located in the northern part of SA, with the Zimbabwean border to the north, Botswana to the west and Mozambique to the east. The province has five districts, namely Capricorn, Vhembe, Mopani, Sekhukhune and Waterberg. Each district is further subdivided into administrative functional municipalities. The total number of public hospitals per district is shown in Table 1. The province has one tertiary hospital, which is a complex comprising two hospitals situated $30 \mathrm{~km}$ apart in Polokwane and Mankweng. The complex delivers tertiary care and deals with some secondary and primary care cases.

\section{Data collection and analysis}

The PERSAL database - a personnel and salary system in the public service - was used to establish the location of the employed medical doctors. The database is the only and the most readily available source of information on health workers for use as a workforce policymaking tool, and it continues to be used to obtain estimates of the distribution of the workforce. The doctor-to-population ratio was used to gauge doctor availability relative to the population size, with low ratios being indicative of doctor need. From the South African Population Census of 2011, we obtained data on the population of each district. ${ }^{24}$ Personnel data were exported from the PERSAL database to a Microsoft Excel spreadsheet for cleanup and analysis.

\section{Ethical consideration}

A descriptive study was conducted in the public sector hospitals of the Limpopo Province, SA. Ethical approval for the study was obtained from the University of Limpopo Ethics Committee - Polokwane campus (Ref: PMREC $87 / 2015)$, and permission to conduct the study was acquired from the Limpopo Provincial Research Committee (Ref: LP2015RP9-492). To assure anonymity and confidentiality of the participants, data were analysed as a group.

\section{Results}

A total of 887 medical doctors were identified in the PERSAL system as at January 2015. Figure 1 shows the age distribution of the doctors practising in the public sector

TABLE 1: Number of hospitals per district.

\begin{tabular}{lccccc}
\hline Hospital types & Capricorn & Vhembe & Waterburg & Mopani & Sekhukhune \\
\hline Tertiary & 1 & - & - & - & - \\
Regional & - & 1 & 1 & 1 & 1 \\
District & 6 & 6 & 7 & 6 & 6 \\
\hline
\end{tabular}

hospitals of the Limpopo Province during the study period. The mean age of these doctors was $40.1 \pm 11.2$ years (range 24-79 years). The majority of the doctors $(66 \%, 599 / 887)$ were younger than 46 years. Sixty per cent of the doctors $(533 / 887)$ were male and $84 \%(747 / 887)$ were African.

An analysis of each category of medical doctors is presented in Figure 2 and shows that 86\% (766/887) of the doctors were MOs. More than half $(55 \% ; 421 / 766)$ of the MOs had $<5$ years working experience (Grade I), 11\% (81/766) had 5-10 years working experience (Grade II) and 22\% $(165 / 766)$ had $>10$ years (Grade III) working experience. The remaining 13\% (99/766) were clinical managers, of which 56\% (56/99) had < 5 years working experience (Grade 1).

Table 2 shows the doctor-to-population ratio per district in the province. The doctor-to-population ratio for the province as a whole was $16.4 / 100000$. When the data were segregated by geographic location, the ratios, in descending order, were 33.7/100 000 for Capricorn, 20.2/100 000 for Waterberg,

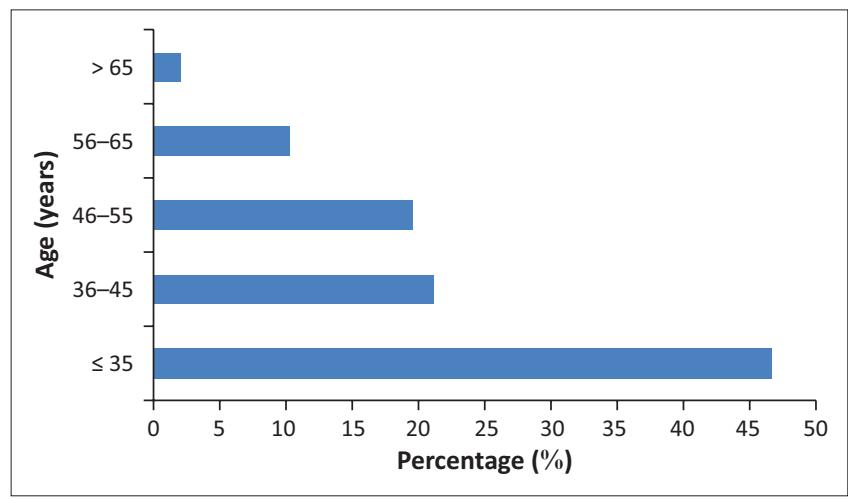

Source: Authors' own work

FIGURE 1: Age distribution of medical practitioners.

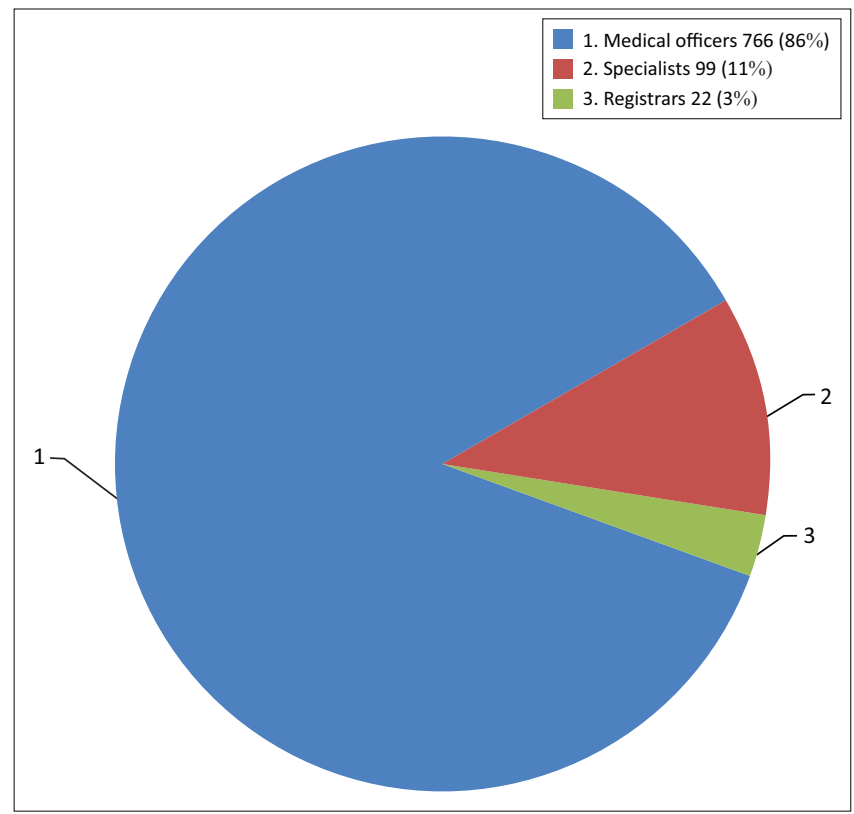

Source: Authors' own work

FIGURE 2: Category of doctors working in the public sector hospitals. 
TABLE 2: Doctor-population ratio in the Limpopo Province.

\begin{tabular}{|c|c|c|c|c|c|c|c|}
\hline \multirow[t]{2}{*}{ Districts } & \multirow[t]{2}{*}{ Population size } & \multicolumn{3}{|c|}{ Number of doctors } & \multicolumn{3}{|c|}{ Density per 100000} \\
\hline & & All doctors ${ }^{\mathrm{a}}$ & Medical officer & Specialist & All doctors & Medical officer & Specialist \\
\hline Capricorn & 1261463 & 425 & 327 & 78 & 33.7 & 25.9 & 6.2 \\
\hline Waterberg & 679336 & 137 & 129 & 8 & 20.2 & 19.0 & 1.2 \\
\hline Sekhukhune & 1077182 & 106 & 104 & 2 & 9.8 & 9.7 & 0.2 \\
\hline Mopani & 1092513 & 106 & 98 & 6 & 9.7 & 9.0 & 0.5 \\
\hline Vhembe & 1294796 & 113 & 108 & 5 & 8.7 & 8.3 & 0.4 \\
\hline Provincial & 5405290 & 887 & 766 & 99 & 16.4 & 14.2 & 1.8 \\
\hline
\end{tabular}

Source: Population size - Statistics South Africa. ${ }^{24}$

a, All doctors includes specialist trainees.

Specialist trainees $(n=22): 5$ in Mopani and 17 in Capricorn District.

9.8/100 000 for Sekhukhune, 9.7/100 000 for Mopani and $8.7 / 100000$ for Vhembe district.

Of the 766 MOs employed within the province, $43 \%(327 / 766)$ were employed in the Capricorn District, of which $71 \%$ $(231 / 327)$ practise within the tertiary hospital complex. In Figure 3, details about the number of MOs practising in the public hospitals of the Limpopo Province is displayed. With regard to specialists, $78 \%$ (77/99) practise within the tertiary hospital complex and 15\% (15/99) practise at regional hospitals. Of the remaining specialists, some were stationed in a district hospital $(2 \% ; 2 / 99)$ and some were part of a district clinical specialist team.

\section{Discussion}

This study explores the geographical distribution of medical doctors employed in the public sector hospitals of the Limpopo Province, SA. Recruitment and retention of a rural health workforce, particularly medical doctors, continues to be a national challenge $\mathrm{e}^{11,12}$ and a major constraint to the delivery of essential health services. ${ }^{25}$ Despite comprehensive rural health workforce recruitment and retention strategies, ${ }^{18,19}$ rural communities continue to face a greater health workforce shortage than do their urban counterparts. In 2008, Lehmann ${ }^{26}$ reported an increase in the doctor-to-population ratio in the public sector hospitals of the Limpopo Province from $6 / 100000$ in 1994 to $17.4 / 100000$ in 2007. In 2010, the ratio deteriorated slightly to $17.2 / 100000 .{ }^{27}$ Our study found that the ratio was $16.4 / 100000$, representing a drop of $4.7 \%$ from 17.2/100 000 in 2010. ${ }^{27}$ Prior to OSD policy, the Limpopo doctors were appointed on a higher notch than the doctors in other parts of SA. This could play a role in the decrease in doctor-to-population ratio and substantially reduce the shift of doctors from public to the private sector. ${ }^{28}$

The World Health Organization (WHO) recommends one doctor for every 1000 people. SA is below this minimum level; however, the country is much better placed than most African countries, ${ }^{12,29}$ but undersupplied when compared with middleincome and high-income countries. ${ }^{5,12}$ The national doctor-topopulation ratios hide internal disparities, ${ }^{30}$ particularly between provinces. Evidently, in 2007, the doctor-to-population ratio in the Limpopo Province was far lower than in Western Cape and Gauteng provinces, ${ }^{26,30}$ which makes it difficult for Limpopo to achieve certain health intervention goals. In this study, further analysis by geographic region revealed that

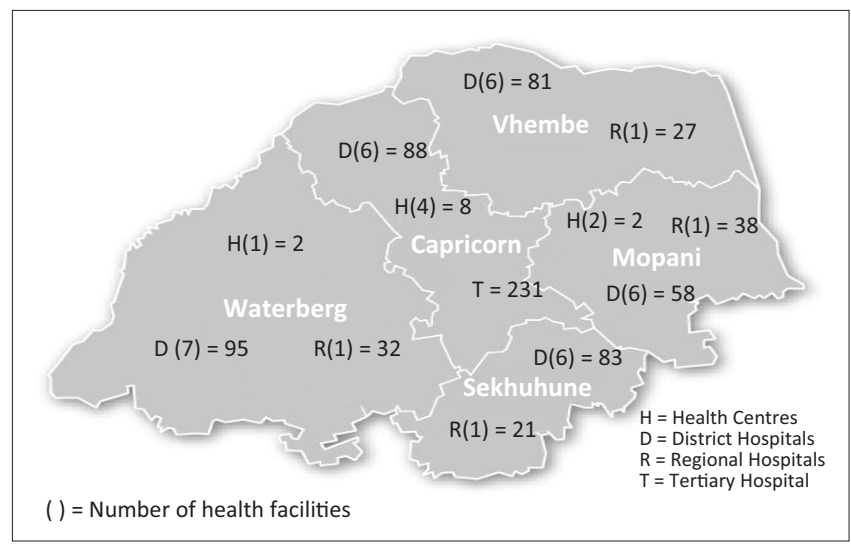

Source: Authors' own work

FIGURE 3: Number of medical officers practising at public hospitals per health district.

Capricorn and Waterberg districts have the largest doctor-topopulation ratio when compared to the other three districts in the province. This might be related to regional social and economic development taking place in Capricorn ${ }^{31}$ and the proximity of the Waterberg District to Gauteng - which is the economic hub of SA. ${ }^{32}$

In many countries maldistribution is arguably a more pressing problem than absolute scarcity. ${ }^{33}$ For example, in Nigeria, ${ }^{34}$ Ghana $^{35}$ and Peru, ${ }^{36}$ doctors are more likely to favour a job in urban areas over rural settings. SA is not an exception; rural doctor shortage has been documented for decades. ${ }^{11}$ Several interventions have been implemented to address shortages of these health professionals in remote and rural areas, such as compulsory community service for graduate medical doctors. ${ }^{18,19}$ This approach has had a shortterm impact on the shortage of doctors in underserved communities, because many doctors leave the rural areas after completing their obligation time, ${ }^{37}$ whereas those who decide to stay lack the knowledge and skills in the management of obstetric and medical emergencies, as well as basic anaesthetic skills. ${ }^{22}$

Furthermore, the government introduced various financial incentives for health workers practising in remote and rural areas. However, financial incentives are not the only factor influencing career choice $18,19,25,38,39$ and their design and implementation is also a challenge. In this study, it was found that more than two-thirds $(78 \%)$ of the specialists and almost half $(43 \%)$ of MOs were clustered in the Capricorn District, of which $73 \%$ of the MOs were working in a tertiary hospital 
complex. This large number of MOs working in the tertiary hospital complex might be related to availability of resources, academic activities and immediate access to consultants.

Evidence from local and international studies has shown that medical school initiatives to train rural medical practitioners have successfully addressed the shortages of medical doctors in remote and rural communities. ${ }^{33,40,41,42,43,44,45}$ Plans for the establishment of a new medical school at the University of Limpopo might help to ease the burden of a shortage of medical doctors in this rural province. However, there are well-documented barriers to expanding the rural health workforce supply which include lack of management capacity, job satisfaction, lack of suppliers or equipment and poor working conditions. ${ }^{28,29,30,39,46,47,48,49}$ Unless these issues are addressed, no matter how many graduates with a rural background are produced, the problem of retaining health professionals in rural hospitals will continue. Moreover, the implementation of OSD policy appears to have reduced the migration of healthcare workers because of low salaries. ${ }^{48,50,51}$ However, this study showed that the maldistribution of healthcare workers remains a major problem in underdeveloped districts. The 'Deprived Area Incentive Scheme' in Ghana and the 'Health Workers Rural Retention Scheme' in Zambia, which includes housing or housing allowances, fast-track promotion and career development opportunities, car or car loans and education grants for staff children among other things, are successful strategies used in keeping doctors in underserved areas..$^{52}$ Thus, these schemes can be tested in this rural province.

\section{Study limitations}

The study used only doctor-to-population ratio for assessing maldistribution of doctors. The ratio was not adjusted by healthcare needs, health status and health service utilisation. In addition, the findings of this study cannot be considered representative of all the provinces in SA. The study was based on the PERSAL data only and was not verified with the institutions directly. It is assumed that a number of specialist trainees (registrars) were still in MOs category in the PERSAL system. Furthermore and more importantly, a significant number of private providers are contracted to work within the public sector on a session basis. The data could not accurately separate the number of private doctors engaged in public sector activity.

\section{Conclusion}

This study demonstrated that there is substantial inequality in the distribution of medical doctors in the public sector hospitals of the Limpopo Province. It was demonstrated that the distribution of medical doctors is clustered in Capricorn and Waterberg Districts. It is also clear that a greater proportion of generalists are concentrated within the tertiary hospital complex, which is disadvantageous for the quality and availability of healthcare in the rural areas of the province. There is no single solution to this multifactorial problem; however, efficient use of the existing workforce and addressing the non-financial issues can be adopted as a short-term response to this challenge, whereas introduction of the schemes mentioned above should be seen as longterm strategies.

\section{References}

1. World Health Organization. The World Health Report 2000 statistical annex. Table 6 Responsiveness of health system, level and distribution in all Member States, WHO indexes, estimates for 1999 [homepage on the Internet]. Geneva: WHO, 2000 [cited 2014 Aug 28]; pp. 184-187. Available from: http://www.who.int/ whr/2000/annex/en/

2. Sheldon GF, Ricketts TC, Charles A, King J, Fraher EP, Meyer A. The global health workforce shortage: Role of surgeons and other providers. Adv Surg. 2008;42:6385. https://doi.org/10.1016/j.yasu.2008.04.006

3. Naicker S, Plange-Rhule J, Tutt RC, Eastwood JB. Shortage of healthcare workers in developing countries - Africa. Ethn Dis. 2009;19(1 Suppl 1):S1-60-S1-64.

4. Pantenburg B, Luppa M, König H, Riedel-Heller SG. Young physicians' thoughts about leaving patient care - Results of a survey in Saxony, Germany. Gesundheitswesen.2014;76(7):406-412.https://doi.org/10.1055/s-0034-1381986

5. Islam N. The dilemma of physician shortage and international recruitment in Canada. Int J Health Policy Manag. 2014;3(1):29-32. https://doi.org/10.15171/ ijhpm.2014.53

6. Schmidt S, Gresser U. Development and consequences of physician shortages in Bavaria. Versicherungsmedizin. 2014;66(1):25-29.

7. Aluttis $C$, Bishaw T, Frank MW. The workforce for health in a globalized context Global shortages and international migration. Glob Health Action. 2014;13(7): 23611. https://doi.org/10.3402/gha.v7.23611

8. Hooper CR. Adding insult to injury: The healthcare brain drain. J Med Ethics. 2008;34(9):684-687. https://doi.org/10.1136/jme.2007.023143

9. Li X, Cochran C, Lu J, et al. Understanding the shortage of village doctors in China and solutions under the policy of basic public health service equalization: Evidence from Changzhou. Int J Health Plann Manag. 2015;30(1):E42-E55. Evidence from Changzhou. Int J
https://doi.org/10.1002/hpm.2258

10. $\mathrm{Xu} \mathrm{H}$, Zhang $\mathrm{W}, \mathrm{Gu} \mathrm{L}$, et al. Aging village doctors in five counties in rural China: Situation and implications. Hum Resour Health. 2014;12(1):36. https://doi. org/10.1186/1478-4491-12-36

11. Brink CJ. Doctor shortage and health services. S Afr Med J. 1971;45(32):883-888.

12. Strachan B, Zabow T, Van der Spuy Z. More doctors and dentists are needed in South Africa. S Afr Med J. 2011;101(8):523-528.

13. Brand-Jonker N. Doctors still in critical shortage [homepage on the Internet] News24 2011 Aug 28 [cited 2015 Mar 1]. Available from: http://www.fin24.com

14. Child K. Is there a doctor in the house? [homepage on the Internet]. The Times 2014 Mar 13 [cited 2015 Mar 1]. Available from: http://www.timeslive.co.za

15. Nicolaides G. Concern over shortage of doctors in SA [homepage on the Internet]. Eyewitness News 2014 [cited 2016 Mar 11]. Available from: http://enw.co.za

16. Rondganger L. SA needs 14351 doctors, 44780 nurses [homepage on the Internet]. DailyNews 2013 [cited 2016 Mar 11]. Available from: http://www.iol. co.za

17. Phakathi B. SA faces uphill battle to retain doctors, nurses [homepage on the Internet]. South African Labour News 2014 [cited 2016 Mar 11]. Available from: http://bdlive.co.za

18. Reid S. Monitoring the effect of the new rural allowance for health professionals [homepage on the Internet]. Durban: Health Systems Trust. Public Service Coordinating Bargaining Council; 2004. Resolution 1 of 2007.

19. Reid SJ. Compulsory community service for doctors in South Africa - An evaluation of the first year. S Afr Med J. 2001;91(4):329-36.

20. Bateman C. Doctor shortages: Unpacking the Cuban solution. S Afr Med J. 2013;103(9):603-605. https://doi.org/10.7196/SAMJ.7323

21. Van Niekerk JP. Internship and community service require revision. S Afr Med J. 2012;102(8):638.

22. Burch V, Van Heerden B. Are community service doctors equipped to address priority health needs in South Africa? S Afr Med J. 2013;103(12):905. https://doi. org/10.7196/samj.7198

23. Erasmus $\mathrm{N}$. Slaves of the state-medical internship and community service in South Africa. S Afr Med J. 2012;102(8):655-658.

24. Statistics South Africa. Statistical release P0302: Mid-year population estimates [homepage on the Internet]. 2013 [cited 2016 Feb 01]. Available from: http:// www.statssa.gov.za

25. Bärnighausen $T$, Bloom DE, Humair S. Human resources for treating HIV/AIDS: Needs, capacities, and gaps. AIDS Patient Care STDS. 2007;21(11):799-812.

26. Lehmann U. Strengthening human resources for primary health care. In: Barron $P$ Roma-Reardon J, editors. South African health review 2008. Durban: Health Systems Trust; 2008, pp. 163-177.

27. Van Rensburg HCJ, Heunis JC, Steyn F. Human resources for health and the health professions in South Africa. In: Van Rensburg HCJ, editor. Health and health care in South Africa. Pretoria: Van Schaik Publishers; 2012, pp. 361-431. 
28. Kotzee TJ, Couper ID. What interventions do South African qualified doctors think will retain them in rural hospitals of the Limpopo province of South Africa? Rural Remote Health. 2006;6(3):581.

29. Blaauw D, Ditlopo $P$, Maseko $F$, et al. Comparing the job satisfaction and intention to leave of different categories of health workers in Tanzania, Malawi, and South Africa. Glob Health Action. 2013;6:19287. https://doi.org/10.3402/gha.v6i0.19287

30. Pillay R. The skills gap in hospital management: A comparative analysis of hospital managers in the public and private sectors in South Africa. Health Serv Manag Res. 2010;23(1):30-6. https://doi.org/10.1258/hsmr.2009.009015

31. Qin X, Hsieh CR. Economic growth and the geographic maldistribution of health care resources: Evidence from China, 1949-2010. China Econ Rev. 2014;31: 228-246. https://doi.org/10.1016/j.chieco.2014.09.010

32. Gauteng Online. The economy of Gauteng [homepage on the Internet]. 2015 [cited 2016 Mar 11]. Available from: http://www.gautengonline.gov.za/Business/ Pages/TheEconomyofGauteng.aspx

33. Chen LC. Striking the right balance: Health workforce retention in remote and rural areas. Bull World Health Organ. 2010;88(5):323, A. https://doi.org/10.2471/ BLT.10.078477

34. Awofeso N. Improving health workforce recruitment and retention in rural and remote regions of Nigeria. Rural Remote Health. 2010;10(1):1319.

35. Ministry of Health, Ghana. Human resource policies and strategies for the health sector 2007-2011 [homepage on the Internet]. Final report. Accra Ghana; 2015 [cited 2016 March 11]. Available from: http://www.who.int/ workforcealliance/countries/Ghana_HRHPolicyPlan_2007_2011

36. Miranda JJ, Diez-Canseco F, Lema C, et al. Stated preferences of doctors for choosing a job in rural areas of Peru: A discrete choice experiment. PLoS One. 2012;7(12):e50567. https://doi.org/10.1371/journal.pone.0050567

37. Reid SJ. Community service for health professionals. In: South African health review 2002 [homepage on the Internet]. Durban: Health Systems Trust; 2003 [cited 2015 Mar 01]. Available from: http://www.hst.org.za/ publications $/ 527$

38. Lehmann U, Dieleman M, Martineau T. Staffing remote rural areas in middle- and low-income countries: A literature review of attraction and retention. BMC Health Serv Res. 2008b;8:19. https://doi.org/10.1186/1472-6963-8-19

39. Henry JA, Edwards BJ, Crotty B. Why do medical graduates choose rural careers? Rural Remote Health. 2009;9(1):1083.
40. Ross AJ. Success of a scholarship scheme for rural students. S Afr Med J. 2007;97:1087-1090.

41. Mathews M, Rourke JT, Park A. The contribution of Memorial University's medical school to rural physician supply. Can J Rural Med. 2008;13(1):15-21.

42. Rabinowitz HK, Diamond JJ, Markham FW, Wortman JR. Medical school programs to increase the rural physician supply: A systematic review and projected impact of widespread replication. Acad Med. 2008;83(3):235-243. https://doi.org/10.1097/ ACM.0b013e318163789b

43. Longombe AO. Medical schools in rural areas - Necessity or aberration? Rural Remote Health. 2009;9(3):1131

44. Tumbo JM, Couper ID, Hugo JF. Rural-origin health science students at South African universities. S Afr Med J. 2009;99(1):54-56.

45. Walker JH, Dewitt DE, Pallant JF, Cunningham CE. Rural origin plus a rural clinical school placement is a significant predictor of medical students' intentions to practice rurally: A multi-university study. Rural Remote Health. 2012;12:1908.

46. Pillay R. Work satisfaction of medical doctors in the South African private health sector. J Health Organ Manag. 2008;22(3):254-268. https://doi.org/10.1108/1477 7260810883530

47. Breier M. Doctors. In: Erasmus J, Breier M, editors. Skills shortages in South Africa: Case studies of key professions. Cape Town: HSRC Press; 2009. pp. P113-P131.

48. George G, Gow J, Bachoo S. Understanding the factors influencing health worker employment decisions in South Africa. Hum Resour Health. 2013;11:15. https:// doi.org/10.1186/1478-4491-11-15

49. Ashmore J. 'Going private': A qualitative comparison of medical specialists' job satisfaction in the public and private sectors of South Africa. Hum Resour Health. 2013;11:1. https://doi.org/10.1186/1478-4491-11-1

50. George G, Rhodes B. Is there really a pot of gold at the end of the rainbow? Has the occupational specific dispensation, as a mechanism to attract and retain health workers in South Africa, leveled the playing field? BMC Public Health. 2012;12:613-627. https://doi.org/10.1186/1471-2458-12-613

51. George G, Atujuna M, Gow J. Migration of South African health workers: The extent to which financial considerations influence internal flows and external movements. BMC Health Serv Res. 2013;13:297. https://doi.org/10.1186/1472-6963-13-297

52. Anyangwe SC, Mtonga C. Inequities in the global health workforce: The greatest impediment to health in sub-Saharan Africa. Int J Environ Res Public Health. 2007;4(2):93-100. 